\title{
Un acercamiento a los valores patrimoniales del edificio de la Facultad de Ingeniería de la Universidad de Costa Rica
}

\author{
Rafael Ángel Venegas Arias
}

Invitado nacional

Investigador independiente

rafael.venegas@ucr.ac.cr

Recibido: 5 de julio del 2017

Aceptado: 13 de noviembre del 2017

\section{Rafael Ángel Venegas Arias}

Licenciado en Arquitectura por la Universidad de Costa Rica. Es asistente curatorial y de adquisición en el Museo de Arte Costarricense y asistente de la Cátedra de Historia del Arte de la Universidad de Costa Rica. Es miembro de ICOM- CR e ICOMOS-CR, donde forma parte del Comité para la investigación de patrimonio moderno en Costa Rica.

\section{Resumen:}

Este ensayo es un acercamiento al edificio de la Facultad de Ingeniería en la Sede Rodrigo Facio Brenes de la Universidad de Costa Rica para su puesta en valor como patrimonio histórico-arquitectónico. Se hace una revisión histórica del inmueble y paralelamente se analizan distintos valores que pueden ser asignados al mismo, los cuales han sufrido un proceso de invisibilización. Los valores analizados en este ensayo son: simbólico, conjunto, objeto de diseño, documento histórico, espacio público y obra de arte; tomando en cuenta conceptos de política, historia, arquitectura e ideología. Para el desarrollo de este ensayo se utilizan los principios de la semiótica, abordando el edificio como un lenguaje que debe ser analizado e interpretado.

Palabras Clave: arquitectura; patrimonio arquitectónico; patrimonio cultural; historia; movimiento moderno.

An Approach to the Patrimonial Values of the Engineering Faculty Building of the University of Costa Rica

\begin{abstract}
:
This essay is an approach to the values of the Engineering Faculty Building in the Campus Rodrigo Facio Brenes of the University of Costa Rica for its consideration as a historical and architectural heritage. The history of the building is reviewed as well as its possible values, which are considered in this essay as underestimated. In this work the building is studied as a symbol, as a complex, as an object of design, as a historical document, as a public space, and as an art piece, using concepts from Politics, History, Architecture and Ideology. The principles of Semiotics are applied to the building, as this is considered as a language that must be analyzed and interpreted.
\end{abstract}

Keywords: architecture; architectural heritage; cultural heritage; history; modern movement. 


\section{Introducción}

Al igual que el lenguaje, las formas arquitectónicas tienen significados connotativos, valores asociados y un contenido simbólico sujetos a una interpretación cultural e individual que puede variar con el tiempo. Así, la arquitectura es la cristalización de tendencias de cada época, el espíritu humano, el sentimiento por su forma, la voluntad y la moral por la utilidad y la ciencia por la técnica; es la creación de espacios estéticos en respuesta a necesidades materiales y espirituales del hombre (Acosta, 2012)

ste ensayo busca hacer un análisis del edificio de la Facultad de Ingeniería, y cómo este funciona como un lenguaje; por ello la pertinencia del análisis desde la semiótica para su consideración como obra de valor artístico, histórico y arquitectónico. Una vez entendido el objeto como obra, se busca poder identificar las estructuras que permitieron su creación y papel en la actualidad, involucrando conceptos de política, arte, espacio público, etc.

Para el desarrollo de este análisis se proponen 5 bloques. En el primero se establece una ubicación general del contexto histórico y del proyecto. En el segundo "Edificio como objeto" ya se estructura dentro de la semiótica a nivel de sintaxis; corresponde esta parte al análisis formal del inmueble, su materialidad y elementos constitutivos, para la identificación de los símbolos. El tercero "Edificio como signo", al nivel de la semántica, en donde identifican los signos y se les otorga un significado. El cuarto, "Edificio como registro vivo", es el último nivel semiótico, la pragmática; en este se hace el análisis de las estructuras históricas, políticas, económicas y sociales, con el fin de identificar su valor simbólico a un nivel más complejo. Y, como quinto punto, se busca enriquecer el análisis desde algunos de los criterios asociados al decoro urbano y espacio público, propuestos por Antoni Remesar. Todo lo anterior con el fin de estudiar por qué y cómo ha llegado este edificio a nuestros días y rescatar sus potencialidades en el futuro.

El objetivo principal radica en la identificación del valor patrimonial de este inmueble para su protección y difusión, con el fin de rescatar del olvido o del desconocimiento los episodios históricos y elementos claves del edificio en su relación con el país y el campus.

\section{Edificio como conjunto}

La arquitectura Moderna ya había llegado al país para los años 30's, principalmente como influencia desde los Estado Unidos, aunque no fue muy aceptada en una sociedad tan conservadora como lo era la costarricense de ese entonces debido a que se mantenía un interés mayor en emular la cultura europea más que a la estadounidense. Lo anterior se evidencia en los estilos arquitectónicos de las nuevas construcciones, principalmente eclécticos con aires afrancesados (ver figura 1).

Figura 1: Morgan, H.G. Calle 1 Este, San José (1922) Fotografía Análoga, Museo Nacional de Costa Rica (NI810703).

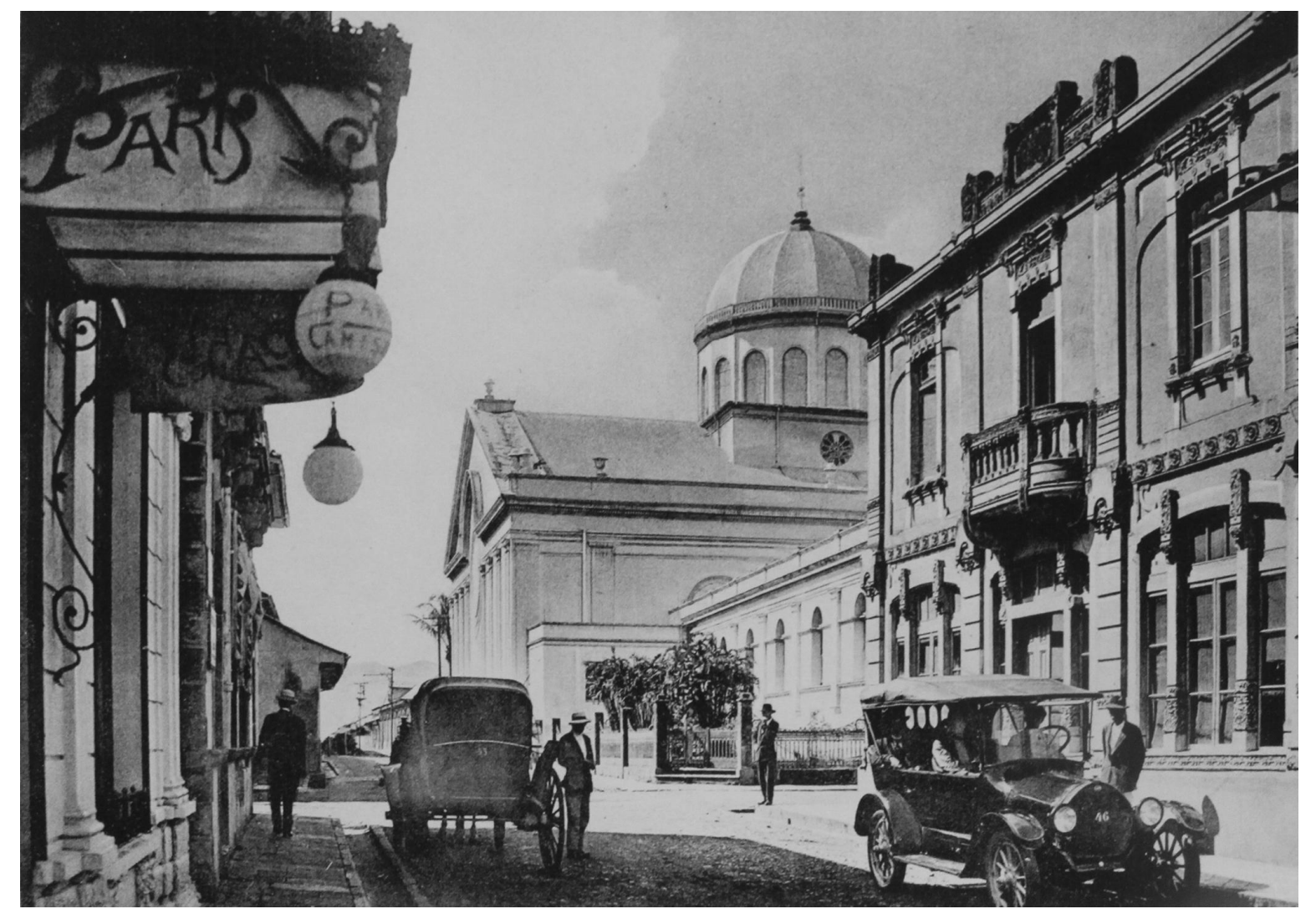


Pero con la implementación de las políticas liberales y la apertura de mercados con Estados Unidos y otros países de la región llegan a Costa Rica una serie de nuevas ideas e ingresos económicos que permitan una movilidad social, lo que traería como consecuencia que grupos sociales emergentes, con acceso a educación y poder político y adquisitivo, marquen un cambio en el gusto de la época. Por ejemplo el proyecto (inconcluso) del Mercado Central de San José para 1940 por el arq. José Francisco Salazar (figura 2) y otros edificios particulares (figura 3)
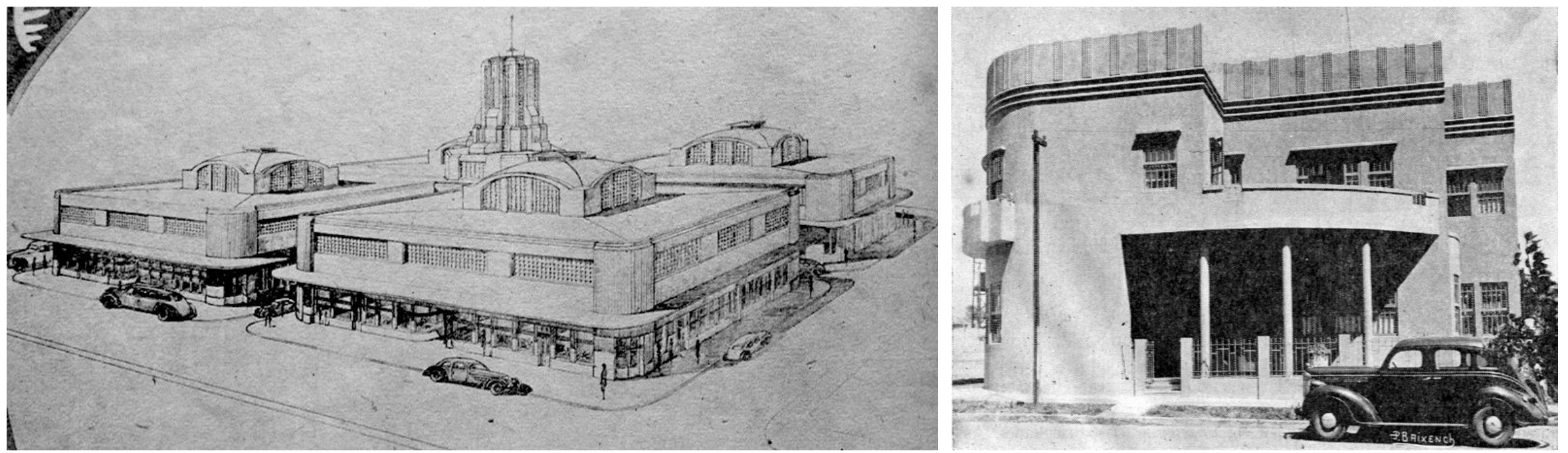

\section{A}

Figura 2: Anteproyecto del Mercado Central de San José (1940). Arq. José Francisco Salazar Quesada. Colección personal Andrés Fernández.

Figura 3:Casa de Roberto Zeledón Castro, avenida 3 y calle 19 (1936). Construida en 1936 para El Ingenio. Colección personal Andrés Fernández.
1 Según el Decreto Fundacional en la Ley de la República № 362 de 1940
El Movimiento Moderno se engloba en una atmósfera de progreso y se ajusta al nuevo gusto; es así que esta tendencia de expresión arquitectónica, que ya había llegado al país, empieza a ponerse en boga, por lo que la arquitectura y las modas extranjeras, como el eclecticismo europeo, empiezan a rechazarse porque se asociaban con retrasos culturales.

Costa Rica entra en un período de grandes cambios tras los efectos de la Segunda Guerra Mundial (1939-1945) y otras situaciones a nivel nacional como la Guerra Civil de 1948. Internamente la Segunda República (que nace con la Junta Fundadora el 19 de abril de 1948) y las Reformas Sociales de 1940 (aparición el Código de Trabajo, las Garantías Sociales, la Caja Costarricense del Seguro Social, entre otras) hicieron al país entrar en el mapa mundial y empujaron a una renovación por medio de políticas de modernización del Estado.

En Costa Rica se da el auge de la década de los años cincuenta (1950-1960), momento en el que el ingreso económico aumentó exponencialmente. Lo anterior se evidencia con algunas cifras de la siguiente manera:

Entre 1944 y 1952 las exportaciones de banano ascendieron de 3,5 millones de cajas anuales a 18 millones, y el valor de embarque de café se duplicó en cinco años, entre 1944 y 1949. El precio del grano de oro en el mercado mundial ascendió de 9 a 68 dólares por quintal entre 1940 y 1956 (Vargas, 2001, p. 292).

Entre 1950 y 1970 más de 50 instituciones estatales fueron creadas (...) Los logros del período son sin lugar a dudas la expansión de la clase media y las notables mejoras alcanzadas en el sector social de la economía costarricense. En otras palabras, los inmensos adelantos experimentados con respecto a la salud, la vivienda, la salubridad, la alimentación y la modernización de la enseñanza contribuyeron, en conjunto, a incrementar el nivel de vida de la población (Vargas, 2001, p. 294).

Es en este momento en que se construyen en la capital edificios que se volverán emblemáticos y marcarán la nueva pauta, eso sí, a nivel de objetos arquitectónicos, como edificios sueltos que se imponen en la trama urbana. Ejemplo de esto es el Banco Central (1959-1963), la Caja Costarricense del Seguro Social de 1966, Banco Angloamericano de 1960 (hoy Ministerio de Hacienda), entre otros, que colocarán a estas arquitecturas como reflejo de la modernidad del gobierno, y marcarán la pauta en la construcción de las grandes obras públicas institucionales a partir de los 50's (figura 4).

Por otro lado, también es importante destacar que bajo la presidencia de Dr. Rafael Ángel Calderón Guardia (1940-1944), se da un fuerte interés en hacer revisión y cambios en los modelos educativos tradicionales, y que será el Lic. Luis Demetrio Tinoco, en calidad de Ministro de Educación (1940-1944), quien crea la Universidad de Costa Rica en $1941^{1}$, cuya antecesora había sido la Universidad de Santo Tomás que fue cerrada por Mauro Fernández por razones políticas, y el establecimiento del código de Educación en 1944. 
Figura 4. Vista aérea de la ciudad

de San José a mediados de siglo XX. (Sin fecha).

Se pueden observar los nuevos edificios modernos del Banco Central de Costa Rica, El Banco Anglo (hoy Ministerio de Hacienda) y la Caja Costarricense del Seguro Social en construcción. Colección Andrés Fernández.
Figura 5: Acuarela del Arq. Santiago Crespo. (1953) @Colección Fotográfica Universidad de Costa Rica/Archivo Universitario Rafael Obregón Loría.

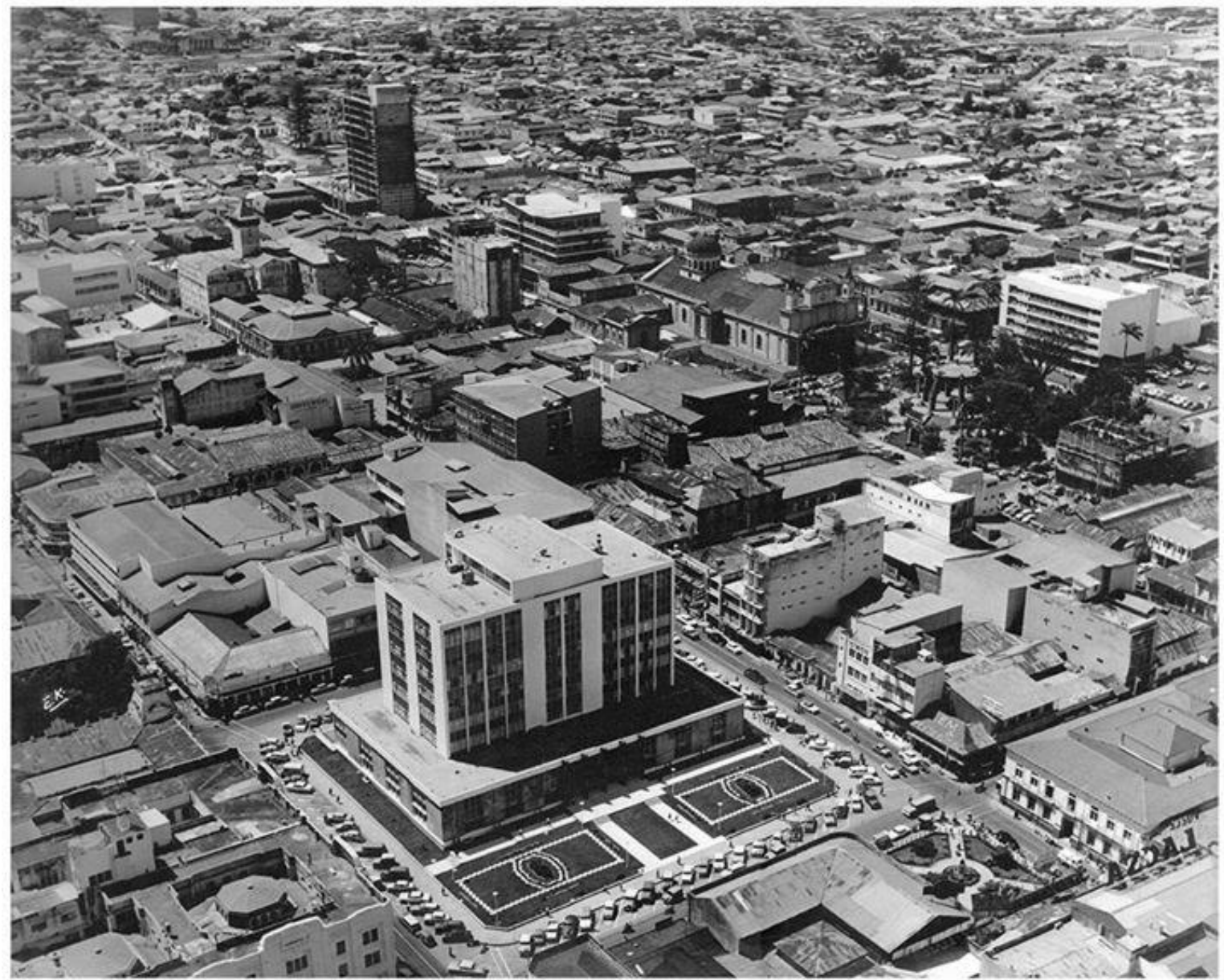

Dentro de este contexto surge el proyecto moderno de mayor envergadura en Costa Rica: el traslado de la Universidad de Costa Rica que se hallaba en una serie de edificios dispersos entre Barrio González Lahmann, y otros sectores de la ciudad, como era el Conservatorio de Música, entre otros, a una sola ubicación debido a la falta de espacio y la necesidad de creación de nuevas escuelas y facultades, además de otorgarle un carácter de unidad institucional. No se había realizado ningún proyecto de estas magnitudes desde el gobierno, aunque sí existían conjuntos grandes de edificios en el país, como las instalaciones de la United Fruit Company en el Caribe, pero desarrollados por empresa privada extranjera.

Proyectada como un solo campus que albergara todas las instalaciones, tal y como se observa en la acuarela del arquitecto Santiago Crespo (ver figura 5), evidencia la integración de los ideales de la arquitectura y el urbanismo moderno, con fuerte influencia de los principios de ciudad planteados por los Congresos Internacionales de Arquitectura Moderna (CIAM) que se venían realizando desde 1929. Lo anterior responde al proceso de modernización al que se enfrentaba toda la región latinoamericana, y a que Costa Rica buscaba estar al nivel de la región.

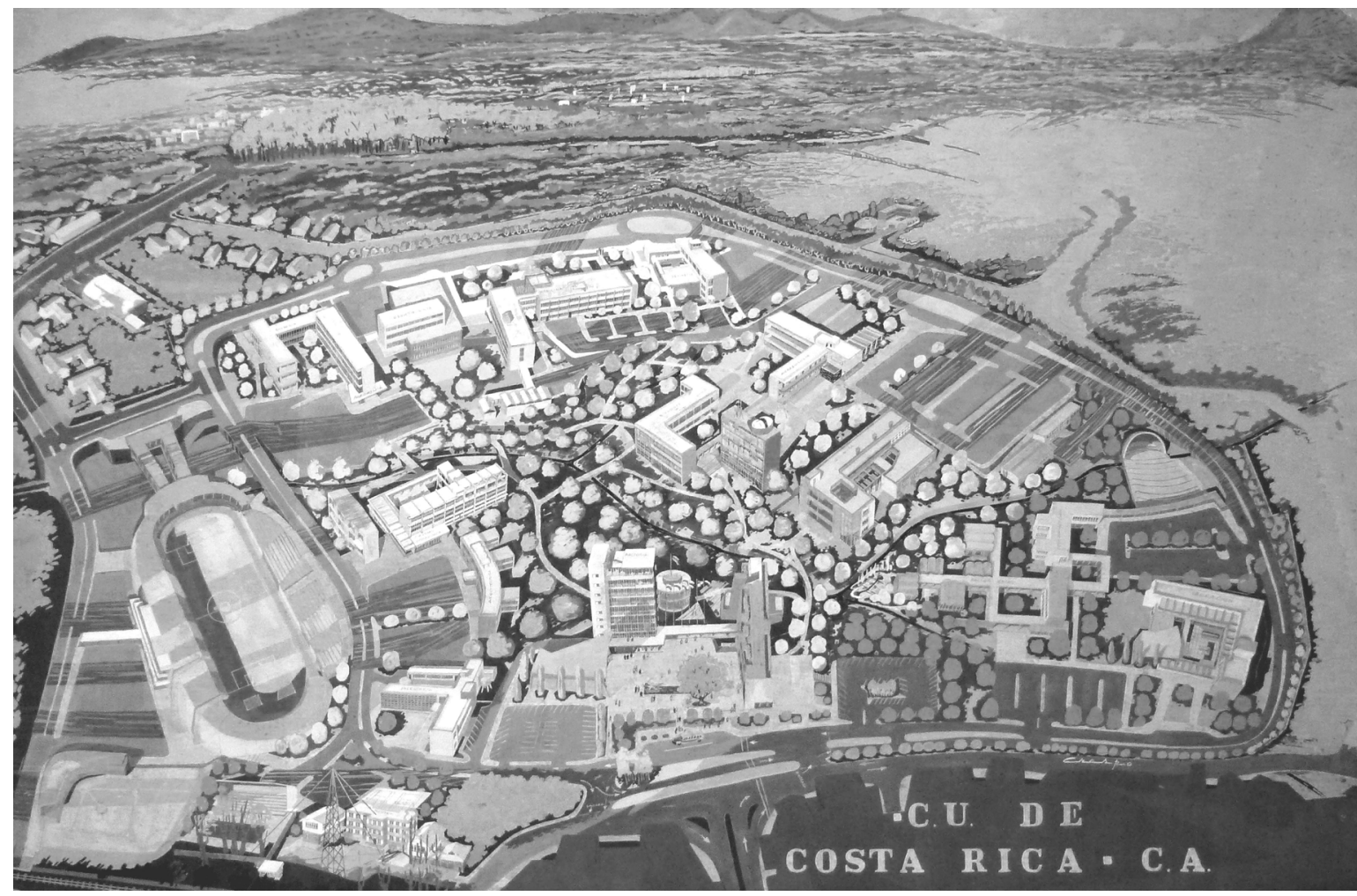


Figura 6: Ciudad Universitaria Rodrigo Facio (Sin fecha). Obtenido en 10 de Septiembre de 2015. Desde https://www.facebook.com/photo php?fbid=705772252809722\&set=gm. 1601683 $276725292 \&$ type $=1$.
Figura 7: Diagrama de ubicación de los edificios del proyecto original. (Reconstruido a partir de uno realizado por Laura Raabe para la exposición "La Historia en concreto: Rodrigo Facio Brenes y la Ciudad Universitaria", UCR, 2012). Elaboración propia
Estos principios urbanísticos podrían resumirse a grandes rasgos en edificios aislados dentro de grandes extensiones de terreno, a los que se accede desde una serie de vías peatonales que corresponden a una trama aún mayor de calles destinadas al automóvil (ver figura 6). Dichos edificios, a pesar de estar concebidos de manera aislada, formaban parte de una totalidad que podía concebirse como conjunto. Cada edificio correspondía a las necesidades específicas de su uso pero manteniendo un lenguaje arquitectónico armonioso.

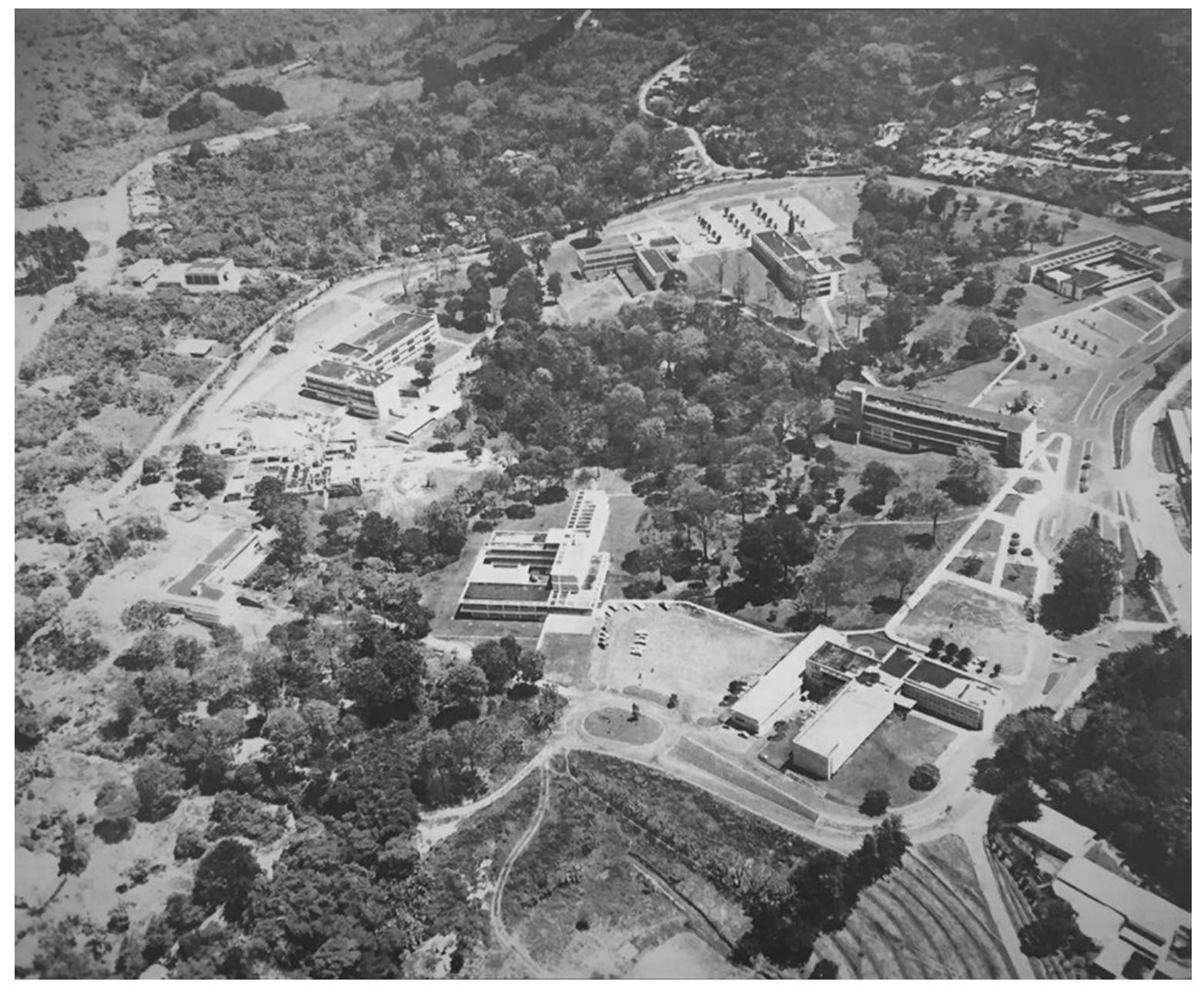

Este proyecto no logró llevarse a cabo en su totalidad debido a la crisis económica que enfrentó el país en los años 70's, lo que provocó modificaciones temporales y ajustes que terminaron por volverse de carácter permanente. El plan de vías vehiculares debía ir primero, y a partir de esta red de caminos se irían construyendo los edificios, de los cuales solo se materializaron 8 (Ver figura 7). El primero en construirse fue la Facultad de Ingeniería, terminado en 1954 y diseñado por el Ing. Rodrigo Masís Dibiasi en colaboración con Jorge Enrique Padilla y un grupo de ingenieros y arquitectos; edificio insigne que engloba los ideales de toda esa época.

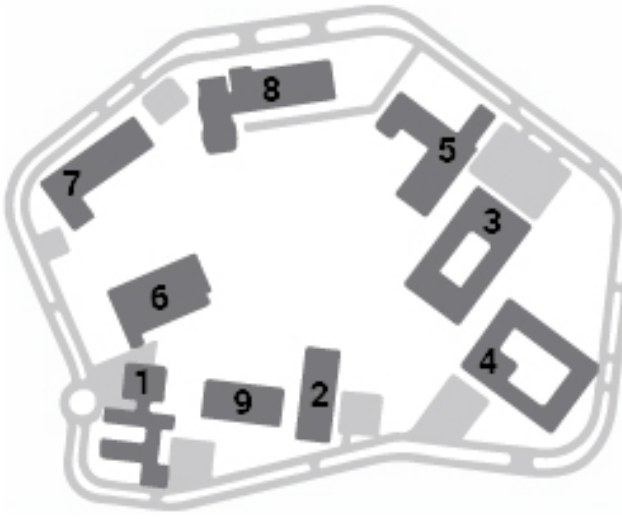

1 Facultad de Ingeniería, 1954

2 Escuela de Estudios Generales, 1957

3 Escuela de Química, 1958

4 Facultad de Educación, 1958

5 Escuela de Microbiología, 1959

6 Facultad de Ciencias Económicas, 1960

7 Escuela Centroamericana de Geología, 1959

8 Facultad de Medicina, 1962

9 Biblioteca Carlos Monge Alfaro, 1970

A este le seguirán la Escuela de Estudios Generales (1957), Escuela de Química (1958), Facultad de Educación (1958), Escuela de Microbiología (1959), Escuela Centroamericana de Geología (1959), Facultad de Ciencias Económicas (1960), Facultad de Medicina (1962), y ya posteriormente y con algunas diferencias notables, la Biblioteca Carlos Monge Alfaro en 1970, único que no formaba parte del proyecto original y que vino a ocupar lo que había propuesto como plaza central y provocaría que no se llevara a cabo la alta torre de Rectoría donde ahora se encuentra la Plaza 24 de abril. 


\section{Edificio como objeto}

El edificio, visto como un objeto arquitectónico², está mediado por los principios e intereses propios de la arquitectura del Movimiento Moderno. El abandono del ornamento y la necesidad de elementos sencillos, que se alejaran del lenguaje historicista, eran la norma y el ideal para estas manifestaciones arquitectónicas, que se desarrollaron en Europa y Estados Unidos de la mano de arquitectos como Le Corbusier, Adolf Loos, Ludwig Mies van der Rohe, entre otros.

A nivel formal, los edificios del campus pueden clasificarse como de estilo racionalista, el cual es una subcategoría dentro de las corrientes arquitectónicas pertenecientes al Movimiento Moderno. Prácticamente todos se construyeron utilizando un lenguaje material en común, el hormigón, recurriendo a cubiertas de losa, columnas redondas y acabados en pintura, paredes con enchapes cerámicos, y con murales o frescos; algunos contaban con muros cortina para delimitar espacialmente y proteger del exterior.

Los materiales y elementos arquitectónicos antes citados, asociados a una revolución constructiva, fueron de fácil implementación en muchas regiones, ya que, debido a la aparente sencillez de los inmuebles, resultaron de gran practicidad a la hora de la construcción: resultaba mucho más fácil y rápido chorrear una retícula de concreto con formaletas utilizando un personal sin conocimientos especializados que contratar maestros canteros para la elaboración de ornamentos en piedra o yesería como era lo usual.

La Escuela Centroamericana de Geología y las Facultades de Ingeniería, Química y Microbiología cuentan con características formales similares. Estas tres se colocan en terrenos con cambios abruptos de nivel, lo que permite contar con un subsuelo o sótano que se abre al exterior; generando una fachada principal a dos niveles, y un cuerpo lateral o posterior de 3 niveles. Esta propuesta compositiva se ha visto deteriorada con la construcción de edificios cercanos o anexos que imposibilitan la visión 360 grados con la que contaban originalmente.

Para las décadas de 1950's y los 1960's, coincidiendo con la construcción del campus, se erigieron en Costa Rica edificios similares al de la Facultad de Ingeniería. Casi todos comparten el mismo lenguaje arquitectónico y fueron destinados para instituciones educativas o edificios de gobierno, como es el caso de la Escuela Unificada República del Perú-Vitalia Madrigal (figura 8) y la Municipalidad de Cartago (figura 9).

Figura 8. Izquierda. Escuela Unificada República del Perú-Vitalia Madrigal. Construida en 1965 y diseñada por la Dirección técnica de arquitectura escolar. (2016). Fotografía del autor.

Figura 9. Derecha. Municipalidad de Cartago. (Sin fecha). Obtenido en 10 de Septiembre de 2015. Desde http://www.cartagohoy.com/wp-content/ uploads/2016/03/51490082.jpg
2 Entendiendo "objeto arquitectónico" como los elementos formales y materiales que componen la obra arquitectónica, es el edificio en sí mismo como una pieza "completa", a partir de la propuesta diseñada por el arquitecto y su correspondiente materialización.

3 Por ejemplo los edificios de la Estación del Pacífico de arq. José Francisco Salazar en 1941 y el Edificio Borges de arq. Paul Ehrenberg Brinkman en la década de 1940
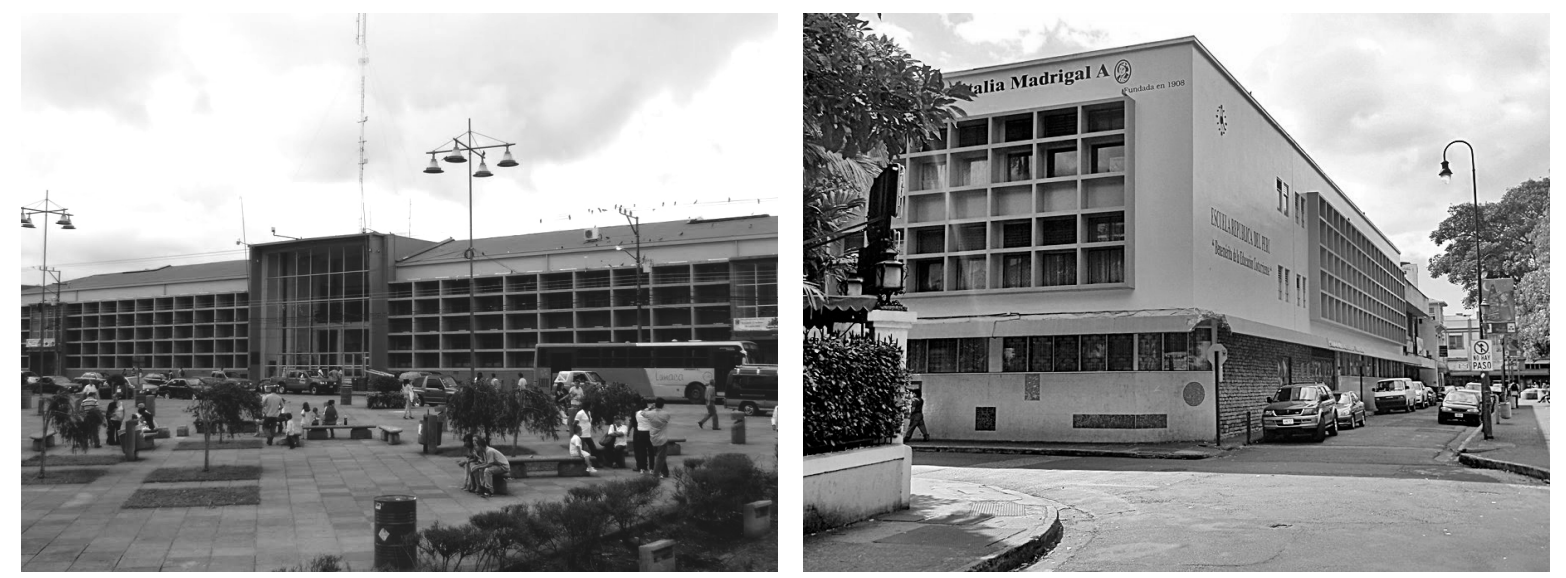

Con estos ejemplos se puede hacer una delimitación del estilo específico que se adoptó para Costa Rica en esa época y para estos usos, ya que edificios del mismo período, pero orientados para estaciones de trenes o edificios comerciales, evidencian un lenguaje distinto donde predomina la curva ${ }^{3}$.

En estos tres casos, los parasoles son construidos en retículas de 5 ó 7 columnas y un número variable de filas, y por lo general cubren toda una fachada del inmueble. La fila central está cegada, ya que con esto se oculta la transición entre el primer y segundo nivel, haciendo que la fachada sea leída como un continuo y de manera uniforme (figuras 10 y 11).

Estos edificios tienden a estar constituidos por volúmenes largos que se extienden a partir de un núcleo, en el cual se colocan las circulaciones verticales. Para el edificio de Ingeniería, la retícula de parasoles está presente solamente en la fachada del acceso principal (sur-oeste), posiblemente por razones climatológicas de protección a las aulas, lo que le confiere un mayor realce en comparación con las otras. 
Figura 10. Izquierda. Inauguración de la Facultad de Ingeniería (1954) @Colección Fotográfica Universidad de Costa Rica/Archivo Universitario Rafael Obregón Loría. Fotografía No. 856

Figura 11. Derecha. 2016, Fachada reticulada de la Facultad de Ingeniería. (2016) Fotografía del autor.

4 Entiéndase "signo" como "aquello que está en lugar de otra cosa, es decir, representa una realidad determinada para alguien que la interpreta" (Arroyo y Berlato, 2012, p. 407).
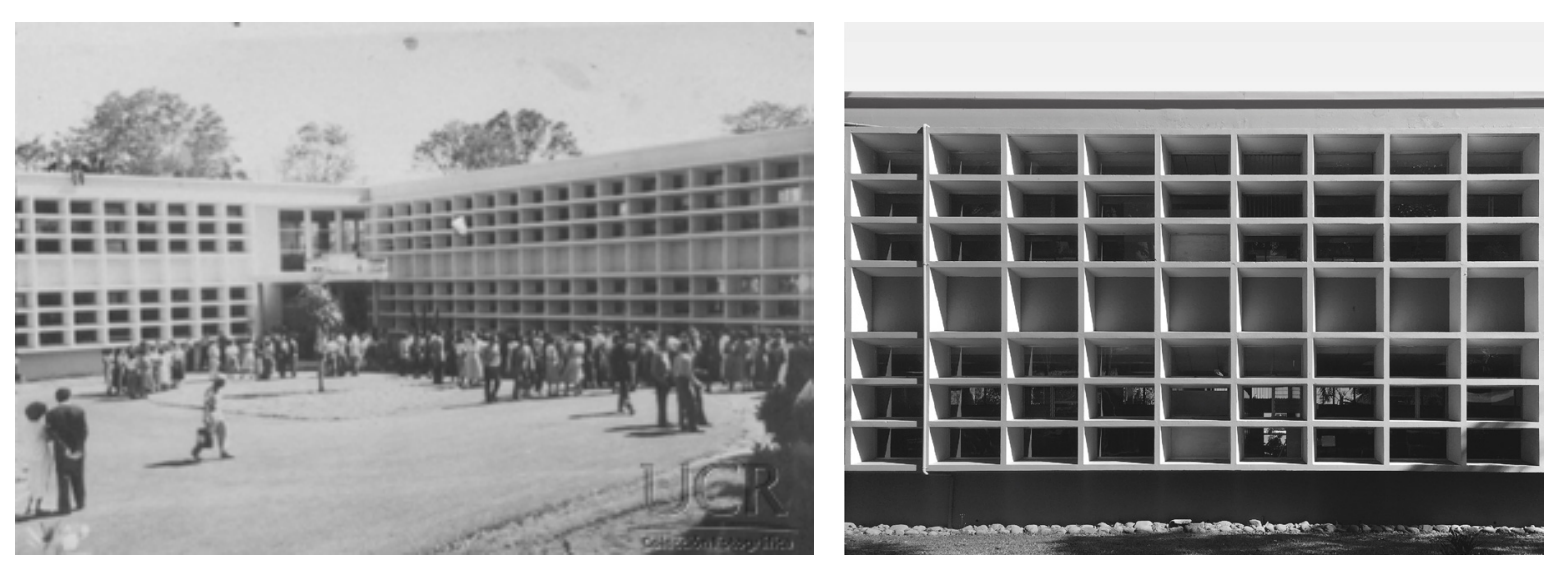

La sencillez en el diseño de este edificio también responde a su función como Facultad de Ingeniería, tratando de plasmar un nuevo lenguaje asociado al progreso, alejándose de la ostentación y decoro para abogar por la pureza de formas que se resumen a lo indispensable.

\section{El edificio como signo ${ }^{4}$}

La búsqueda por un lenguaje puro, alejado del ornamento, se traduce en estos edificios en los volúmenes rectos. La pureza de las líneas se convertirá en un nuevo ornamento: las retículas de los parasoles de las ventanas; llevada al uso mínimo del material en respuesta a la necesidad de protección climática.

Remesar (1997) (para explicar algunos principios de la arquitectura moderna, plantea que "siguiendo las pautas de estas corrientes formalistas, el urbanista tiene por misión, eliminar todo lo superfluo, lo anecdótico, en beneficio de unas formas sencillas" (Remesar, 1997, p. 124). Por lo tanto, se evidencia que los edificios y el urbanismo se separan de los lenguajes históricos, y deben por ello recurrir a una nueva búsqueda formal. Esto los llevará a la exploración de las escaleras, pasillos y columnas, lo que definirá el nuevo lenguaje: serán estos el sostén y alma del edificio; la estructura ya no se oculta, por el contrario, se muestra y se le dan valores plásticos.

Desde estos elementos del nuevo lenguaje arquitectónico se pueden valorar algunas diferencias significativas con respecto a la arquitectura anterior. El edificio de Ingeniería no cuenta con una fachada noble o frontal (como los templos clásicos o los palacios renacentistas, barrocos y neoclásicos); por el contrario, los diferentes volúmenes se acomodan según el terreno. Desaparece la puerta principal para dar lugar a múltiples accesos (originalmente, al edificio se le podía acceder por tres puertas principales, y varios accesos a los pasillos). Esta configuración permite una nueva relación interiorexterior. Esto no solo se aplicará a los edificios, es una nueva visión global de la construcción y organización del espacio:

Este urbanismo (el moderno) se basa, también en la fe ciega en los avances científicos y tecnológicos. La introducción de nuevos materiales, - hormigón, hierro, acero, cristal,- y nuevos modos de producción del edificio - estandarización, elementos modulares-, se combinan con el estudio de las posibilidades de crecimiento en vertical que los cálculos de estructuras, y los propios materiales, permiten (Remesar, 1997, p. 121).

Desde la misma materialidad son identificables los nuevos valores. El concreto, que ya se había utilizado en construcción, toma el protagonismo, y es a partir de sus posibilidades de adaptación que se vuelve el configurador de las formas. Un nuevo gusto por el material aparece. Históricamente, los materiales se "maquillaban" porque su función era estructural; ahora, el concreto se exalta por sus cualidades plásticas y entra en el juego de la nueva estética. Esto puede traducirse a un gusto por lo racional, lo real; la pureza del material es una señal de que lo vital e importante está a la vista, y no oculto tras un ornamento, tal y como planteaba incipientemente en 1908 Adolf Loos en "Ornamento y Delito":

No lloréis. La grandeza de nuestra época radica en el hecho de que es incapaz de crear un ornamento nuevo. Hemos vencido al ornamento. Hemos decidido finalmente prescindir de él. ¡Observad! ¡Se acerca el momento en el que las calles de las ciudades brillarán como muros blancos! Como Sión, la ciudad santa, la capital del cielo. Entonces lo habremos conseguido (Loos, 1908). 
Figura 12. Izquierda. Inauguración de la Facultad de Ingeniería (1954). En la fotografía de izquierda a derecha: Alberto Bolaños, la educadora Emma Gamboa Alvarado (declarada benemérita de la patria en 1980), el rector Rodrigo Facio Brenes, el entonces presidente José Figueres Ferrer y Rodrigo Sancho.@Colección Fotográfica Universidad de Costa Rica/Archivo Universitario Rafael Obregón Loría

Figura 13. Central. Inauguración de la Facultad de Ingeniería (1954). Bendición del edificio por parte de la Iglesia Católica. CColección Fotográfica Universidad de Costa Rica/Archivo Universitario Rafael Obregón Loría. Fotografía No. 936

Figura 14. Derecha. (1954). Inauguración de la Facultad de Ingeniería. En la fotografía de izquierda a derecha: el entonces presidente José Figueres Ferrer, el rector Rodrigo Facio Brenes, y Rodrigo Sancho. CColección Fotográfica Universidad de Costa Rica/Archivo Universitario Rafael Obregón Loría. Fotografía No. 933
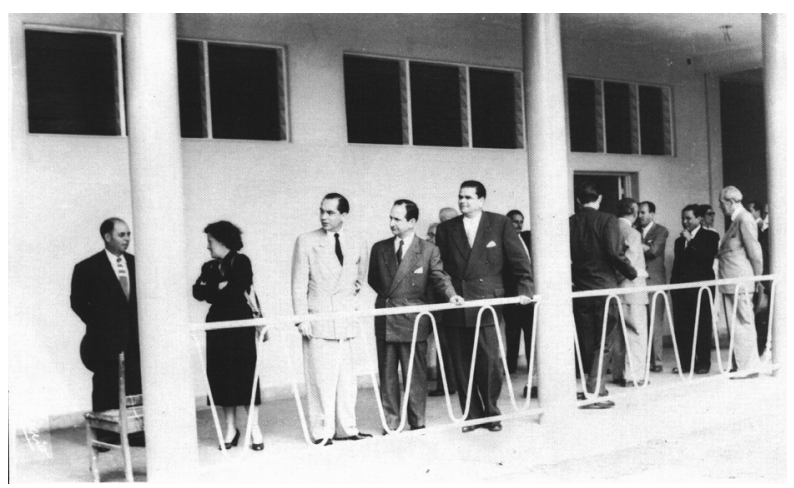

La limpieza de volúmenes, la multiplicidad de accesos y la materialidad marcan la búsqueda por un lenguaje distinto, que se puede leer como una nueva visión de mundo, en la que la ciencia y la tecnología pasarán a regir todos los campos del saber. Por lo anterior, fue el lenguaje ideal escogido para el edificio de la Facultad de Ingeniería, ya que esta arquitectura está muy ligada al concepto de progreso, y este al del saber racional y la ciencia. La facultad de Ingeniería se planteaba como el baluarte de los avances científicos en torno a las carreras técnico-profesionales, y sería la generadora de los trabajadores que participarían en la modernización del país.

En síntesis, la utilización de un nuevo lenguaje y materiales le permite al edificio identificarse como un signo de los cambios de la época asociado a ideas de progreso, además de ser un elemento más en la campaña política nacional que se desarrolla en el siguiente punto.

\section{El edificio como registro vivo}

El Movimiento Moderno se constituye no solo como una corriente arquitectónica, sino también como una lucha por una nueva sociedad. Lo anterior teorizado por Tournikiotis:

(...) [el] movimiento moderno (...) se mueve en la dirección del colectivismo. (...) la nueva arquitectura que proclaman equivale a una nueva sociedad, y por eso en Haufmann y Pevsner podemos identificar el proyecto del Movimiento Moderno con el proyecto de una sociedad distinta (Tournikiotis, 2001, p. 41)

Por lo anterior, se evidencia el poder simbólico que proponía la arquitectura del Movimiento Moderno como propaganda política de la Segunda República en Costa Rica: fue este el lenguaje que prácticamente todas las naciones latinoamericanas tomaron para evidenciar su modernización. Será para 1956 que este lenguaje tome una fuerza indiscutible para la región, con la construcción de Brasilia con arquitectura gubernamental y, con mayor relación, la construcción en 1952 del campus de la Universidad Nacional Autónoma de México.

Desde su concepción, el campus de la UNAM marcó un hito a nivel mundial. Es interesante que tan solo 2 años después ya Costa Rica contara con un campus trazado, inspirado por el mexicano y otros de la región. Esto reflejaba a nivel nacional e internacional las políticas de modernización del estado y evidenciaba su posición a la vanguardia. Esta era la imagen que Costa Rica, desde el Estado, mostraba al mundo en su lucha por una nueva sociedad que apostaba por el progreso, colocándose a la cabeza en relación con otros países latinoamericanos.

Ya fuera del aspecto físico del edificio, este es un verdadero monumento a los cambios políticos y económicos que llevaron a la Universidad de Costa Rica al puesto que tiene hoy dentro del imaginario nacional. El edificio evidencia la importancia que tomaron los cambios en las directrices educativas y, desde luego, es un reflejo ideológico de una estructura política, como lo fue la Segunda República, que se afianzaba en la imagen proyectada por el Movimiento Moderno para consolidar su discurso (figuras 12, 13 y 14).
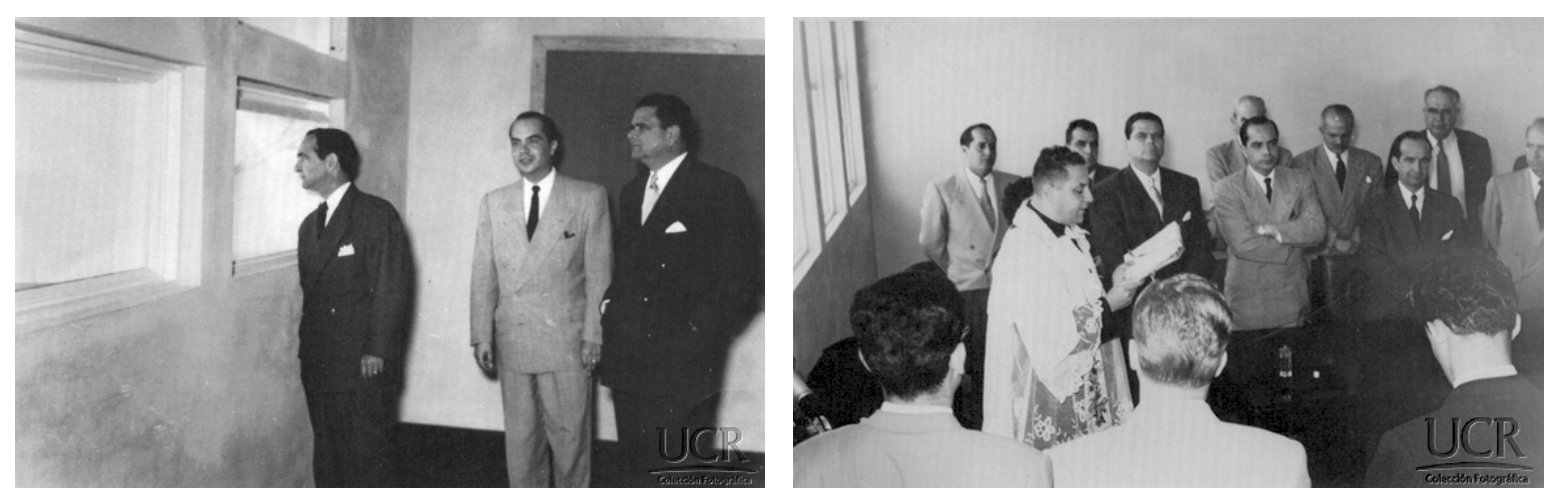

El edificio desde un primer momento se convirtió para la Universidad y el Estado en un objeto simbólico y estandarte de las políticas gubernamentales, las cuales consistían para ese momento en "la visión racional del mundo, la creencia en un Estado centralizado, la búsqueda de una hegemonía estatal mediante un crecimiento físico y cualitativo, y a creencia en la necesidad de una transformación total para alcanzar el progreso" (Vargas, 2001, p. 266). Esto se refuerza en la reforma educativa y la necesidad de contar con 
Figura 15. Izquierda. Discurso de Kennedy con > el edificio de Ingeniería como fondo (1963). Colección personal Andrés Fernández.

Figura 16. Derecha. Fotograma de la salida del Helicóptero con J. F Kennedy con el Edificio de ingeniería como fondo (1963). Obtenido el 10 de Octubre de 2015. Desde https://www.youtube.com/ watch?v=aeXRLvcPp-l
5 La "Pasada de Derecho" es una tradición que se remite a un enfrentamiento entre los estudiantes de ingeniería y derecho por el paso de estos últimos al campus Rodrigo Facio, ya que Derecho fue la última facultad en dejar las instalaciones en Barrio González Lahmann. El conflicto, según algunas historias, se remite a la falta de espacio y la lucha para que no le asignaran el edificio correspondiente, esperando que fuera entregado a ingeniería. Por lo tanto cada año los estudiantes de Derecho desfilan desde su edificio hacia ingeniería con la intención (ya modificada con los años) de arrojarles frutas podridas y huevos. (Parafrasenado a Carvajal y Padilla, 2012). Actualmente el evento suele finalizar con un muy concurrido partido de futbol entre derecho e ingeniería en el Estadio Universitario. profesionales de múltiples áreas que se formaran para impulsar el crecimiento y mejora del país, principalmente en términos económicos y sociales.

No es casualidad que precisamente este primer edificio moderno del campus, fuera donde John F. Kennedy diera su discurso en la visita al campus en 1963. Es importante destacar que con esta visita, Costa Rica se definió como aliado de los Estados Unidos, tal y como afirma David Díaz:

La visita de Kennedy fue un momento crucial para afirmar el anticomunismo y el carácter aliado de Costa Rica junto a Estados Unidos. En sentido estricto, la reunión en Costa Rica representaba la afirmación del frente anticomunista centroamericano y el cierre de filas de esta región al lado de los Estados Unidos contra la Unión Soviética (Díaz, 13 de diciembre de 2015)

Lo anterior le otorga un papel simbólico dentro de la construcción de la historia del país y, gracias a los medios de comunicación, las imágenes del campus, específicamente el edificio en cuestión, fueron difundidas a nivel mundial (ver figuras 15 y 16); y, con esto, el posicionamiento de Costa Rica como una nación "progresista" en la región, que por medio de la arquitectura moderna del campus hace referencia a los vínculos culturales que se incorporarían al país, y la relación directa con la influencia del Estilo Internacional proveniente principalmente de Estados Unidos.
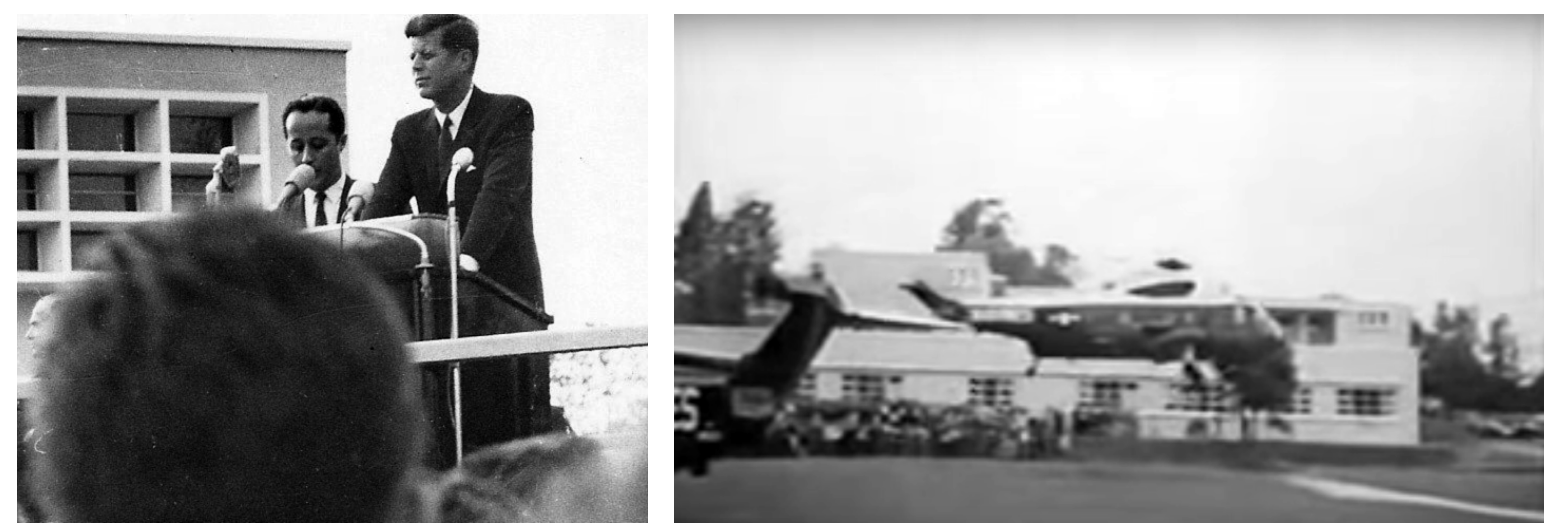

El edificio ha ocupado un espacio preponderante dentro del campus. Es de los pocos que cuentan con una ubicación y visibilidad preponderante en cada una de sus fachadas, ya sea desde el sector del pretil (que con los años, a pesar de no construirse la plaza, se consolidaría como el centro de la Universidad), desde la entrada principal y desde la vía que comunica con el sector suroeste hacia la actual Rectoría.

A lo largo del tiempo, se ha intervenido el edificio con soluciones que parecen no respetar el diseño original y que responden más a resolver problemas funcionales, esto también influenciado por la capacidad de inversión del momento. Es así que con cada intervención ha perdido paulatinamente su expresión plástica original y estas han menospreciado su valor histórico simbólico (ver figura 17); lo anterior reforzado por el desconocimiento general de la población de la historia del campus y su papel en la política nacional e internacional. Se encuentra respaldado en:

Las modificaciones en el paisaje que acabamos de reseñar (reducción de áreas verdes y superposición y multiplicación de soluciones individuales y aisladas), junto con la pérdida por demolición o superposición indiscriminada de agregados a los edificios (...) contribuyen fuertemente a la pérdida de la identidad de la institución desde el punto de vista de su imagen, así como también a la pérdida del sentido de lugar fundamental en la percepción y bienestar de los usuarios (Jankilevich, 2011, p. 28)

El edificio no ha desaparecido del imaginario universitario debido a su estratégica ubicación que le permitió formar parte, aunque fuese de manera de telón de fondo, de las grandes actividades, como las tradicionales pasadas ${ }^{5}$ (ver figuras 18 y 19) o los conciertos de la Semana Universitaria, las que refuerzan de cierta manera la continuidad y asociación del este inmueble con el resto del campus. 
Figura 17. Tabla con diagramas de las intervenciones más significativas en el edificio. Elaboración propia.

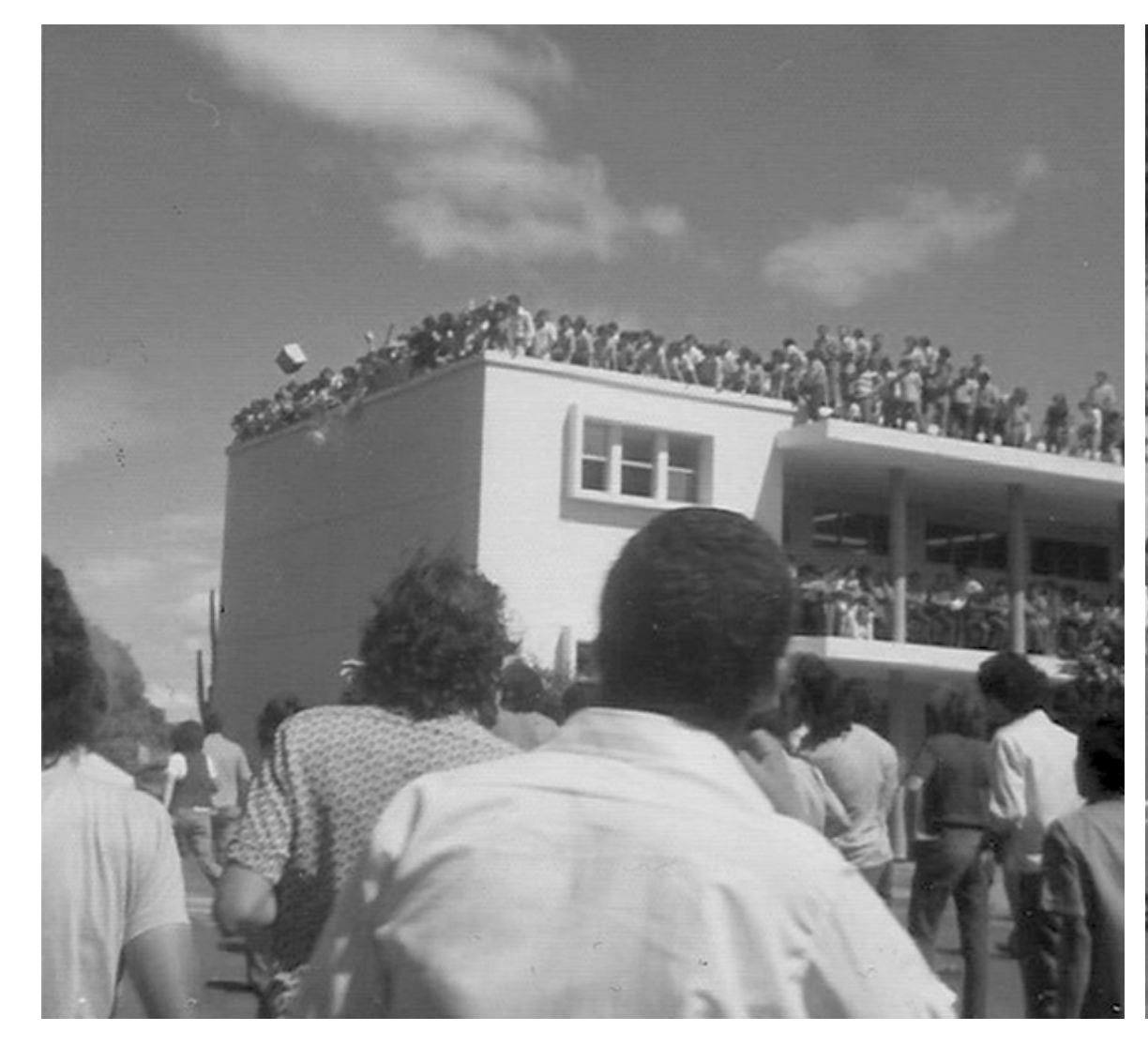

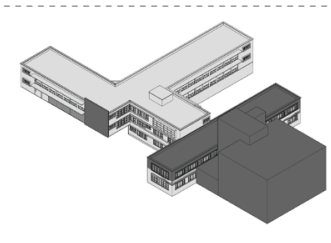

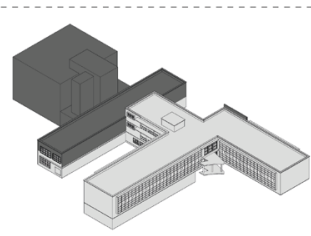

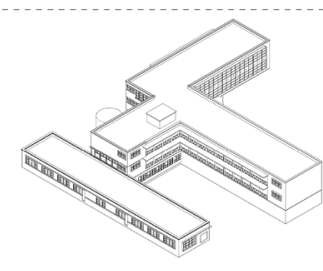

1952

El edificio histórico: Este es el proyecto original, el cual está finalizado para 1952.

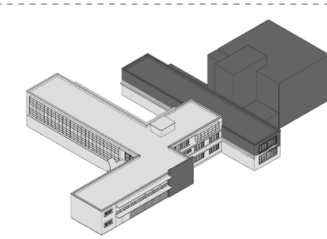

1968

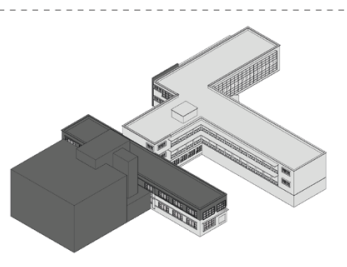

La torre: Debido a la falta de espacio de agrega una torre de 5 niveles al norte y se duplican en un segundo nivel el volumen de la fachada norte.
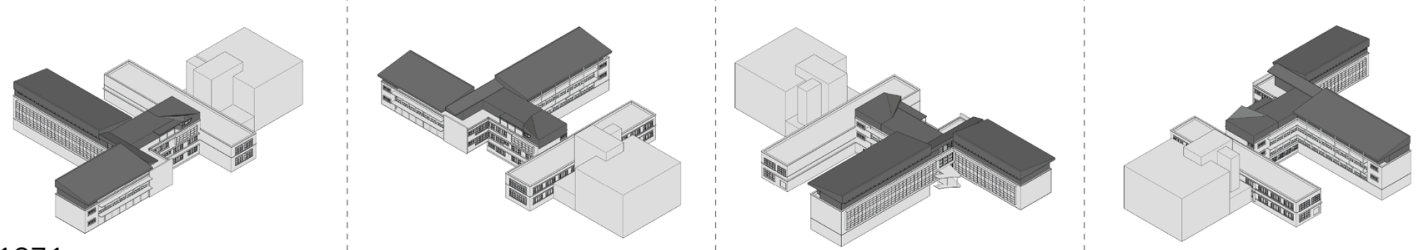

Tercer nivel: Aprovechando la cubierta de concreto existente se construyó el agregado con estructura metálica y cerramientos livianos.

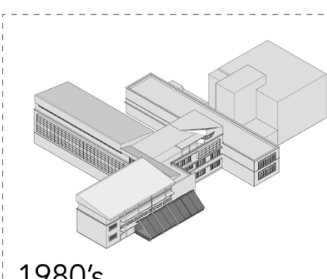

1980's

Añadidos varios: Se contruyen los "estudiaderos", y se agregan pequeñas instalaciones y añadidos que cierran la fachada este.

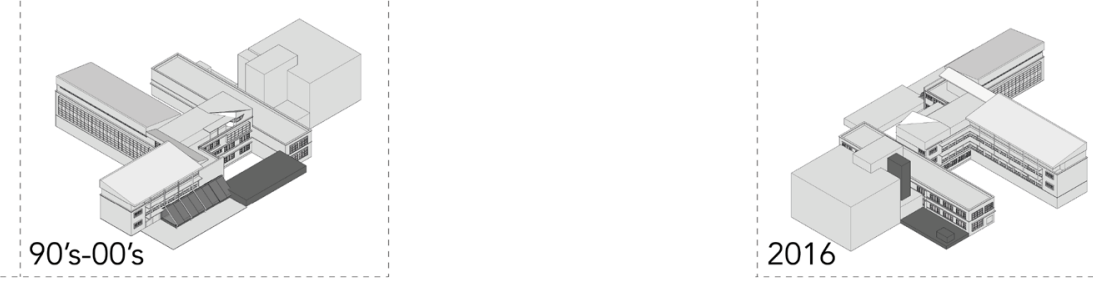

Adaptación: Se construye un ascensor e instalaciones eléctricas

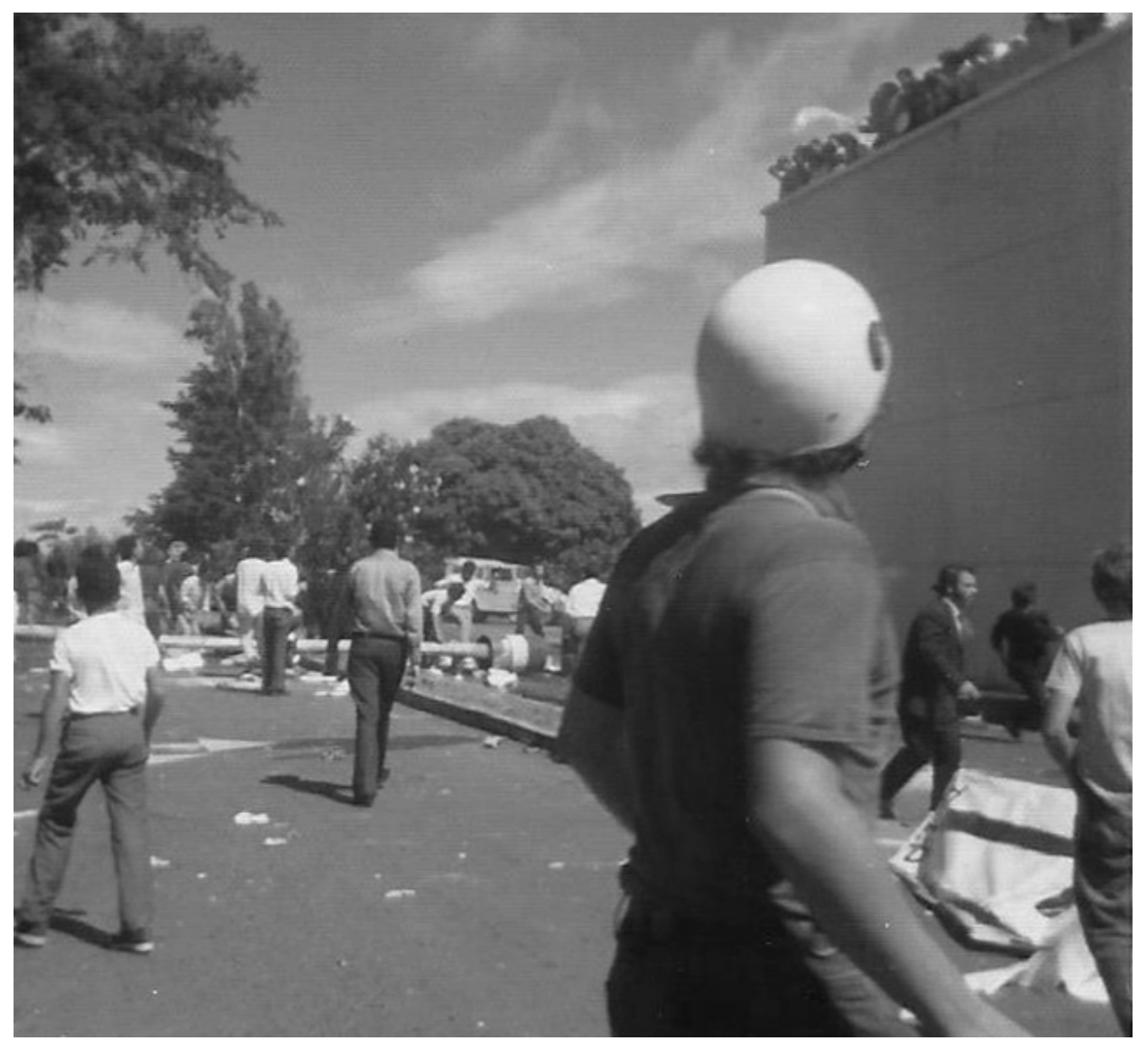

Figura 18. Izquierda. 1975, Pasada de Derecho

en el Edificio de Ingeniería. (1975). Obtenido

en 10 de Septiembre de 2015. Desde https://www.

facebook.com/photo.php?fbid=10153305512

692732\&set=pcb. $1785522378341380 \&$ \&ype

$=1$ \&theater

Figura 19. Derecha. Pasada de derecho

(1975). Obtenido en 10 de Septiembre de

2015. Desde https://www.facebook.com/photo.

php?fbid $=10153305512692732 \&$ set $=$ pcb.

1785522378341380\&type=1\&theater 


\section{El edificio como espacio público}

A partir de los criterios formulados para la definición del nuevo decoro urbano, montados principalmente en lo expuesto por Antoni Remesar y en lo expuesto por Jordi Borja, el edificio de la Facultad de Ingeniería de la Universidad de Costa Rica puede ser analizado, para determinar su papel como espacio público, partiendo de la siguiente definición:

El espacio público no tiene como opuesto el espacio privado. (...) El espacio público es un contenedor vacío de sentido, una necesaria reserva de territorio, para ejecutar el sentido de la ciudad. El espacio público toma sentido en otra oposición que nada tiene que ver con la privado público. La oposición que propongo es "proyecto urbano3" / "proyecto de uso social" (Remesar, 1997, p. 71)

El campus de la Universidad es un espacio administrado bajo la lógica de lo privado con reglamentación, y personal de control y seguridad propios; pero es un espacio público si partimos de que es lugar donde se desarrollan actividades sociales no excluyentes, lo anterior apoyado en:

El espacio público tiende fundamentalmente a la mezcla social, hace de su uso un derecho ciudadano de primer orden, así el espacio público debe garantizar en términos de igualdad la apropiación por parte de diferentes colectivos sociales y culturales, de género y de edad (Borja, 2000, p. 10)

El espacio público supone pues dominio público, uso social colectivo y multifuncionalidad. Se caracteriza físicamente por su accesibilidad (...) La calidad del espacio público se podrá evaluar sobre todo por la intensidad y la calidad de las relaciones sociales que facilita, por su fuerza mezcladora de grupos y comportamientos; por su capacidad de estimular la identificación simbólica, la expresión y la integración culturales (Borja, 2000, p. 28)

Si evaluamos con lo anterior, prácticamente todos los edificios del Estado, a pesar de ser propiedad del colectivo, son obras de carácter privado, ya que ofrecen una sensación de amenaza al usuario, utilizando políticas de control y represión muy marcadas, como las cámaras de video, rejas, sensores, oficiales de seguridad, etc. Esta situación se ha maximizado en los últimos años, eliminando y enrejando las áreas públicas alrededor de los edificios, como en los casos de la Contraloría General de la República, el Hospital Dr. Rafael Ángel Calderón Guardia y las Oficinas Centrales de la Caja Costarricense del Seguro Social. Lo anterior genera una limitación de uso que no invita a apropiarse y familiarizarse con estos inmuebles, donde cada vez está más limitado el acceso, y cuando se da es para realizar las actividades estrictamente necesarias.

Pero si evaluamos con lo expuesto por Borja, los edificios de la Universidad se encuentran en una situación muy distinta. Partiendo por el hecho de que cualquier persona puede ingresar a los edificios sin ninguna justificación (a excepción de algunas escuelas o facultades cuyo control debe realizarse por cuestiones de seguridad, como Informática o laboratorios con equipos especializados).

Según políticas universitarias, cualquier ciudadano puede ingresar al campus, a los edificios y participar de oyente (dependiendo del curso). Por lo tanto, todos podemos ingresar, descansar, aprovechar servicios o incluso simplemente estar dentro de estos edificios. Algunos cuentan con mayores facilidades, como Letras, Educación, Generales, y para este caso, Ingeniería.

Si el edificio, como quedó evidenciado en las secciones anteriores, es una obra artística-arquitectónica (por su calidad plástica, valor como documento histórico, la materialización de un discurso político e ideológico y la evidencia del ideal de toda una época) pero también es un espacio público, ya que todos tenemos derecho a circular por el edificio, ¿no sería entonces que el edificio, en términos generales, se comporta como la primera obra de arte público del campus?, y por lo tanto este debe concebirse como un espacio destinado para actividades de carácter público.

Con la construcción de los edificios de la primera generación, se evidenciaba una manera distinta de concebir el espacio: estos inmuebles se proyectaban ya no como núcleos funcionales aislados, pues los edificios del campus original estaban planteados con fuertes vínculos con su emplazamiento: 
Figura 20: Almuerzo universitario con el edificio > de Ingeniería de fondo (1954) OColección Fotográfica Universidad de Costa Rica/Archivo Universitario Rafael Obregón Loría. Fotografía No. 1049
Lo importante del primer plan maestro era que la vegetación se involucrara con los edificios. Eran edificios de planta libre, muy fácil de circular a través de ellos, y que no se sentían como una imposición en el paisaje (Zuñiga citando a Chaverri, 2017).

Estos edificios, y específicamente el de Ingeniería, con sus múltiples entradas, patio central y corredores porticados abiertos, se disponían de manera que fuesen aprovechados por los usuarios para que pudieran apropiarse de estos espacios en las horas de ocio (ver figura 20). Por lo tanto, se proyectaba como un lugar para usos múltiples, y no solamente como recinto educativo tradicional.

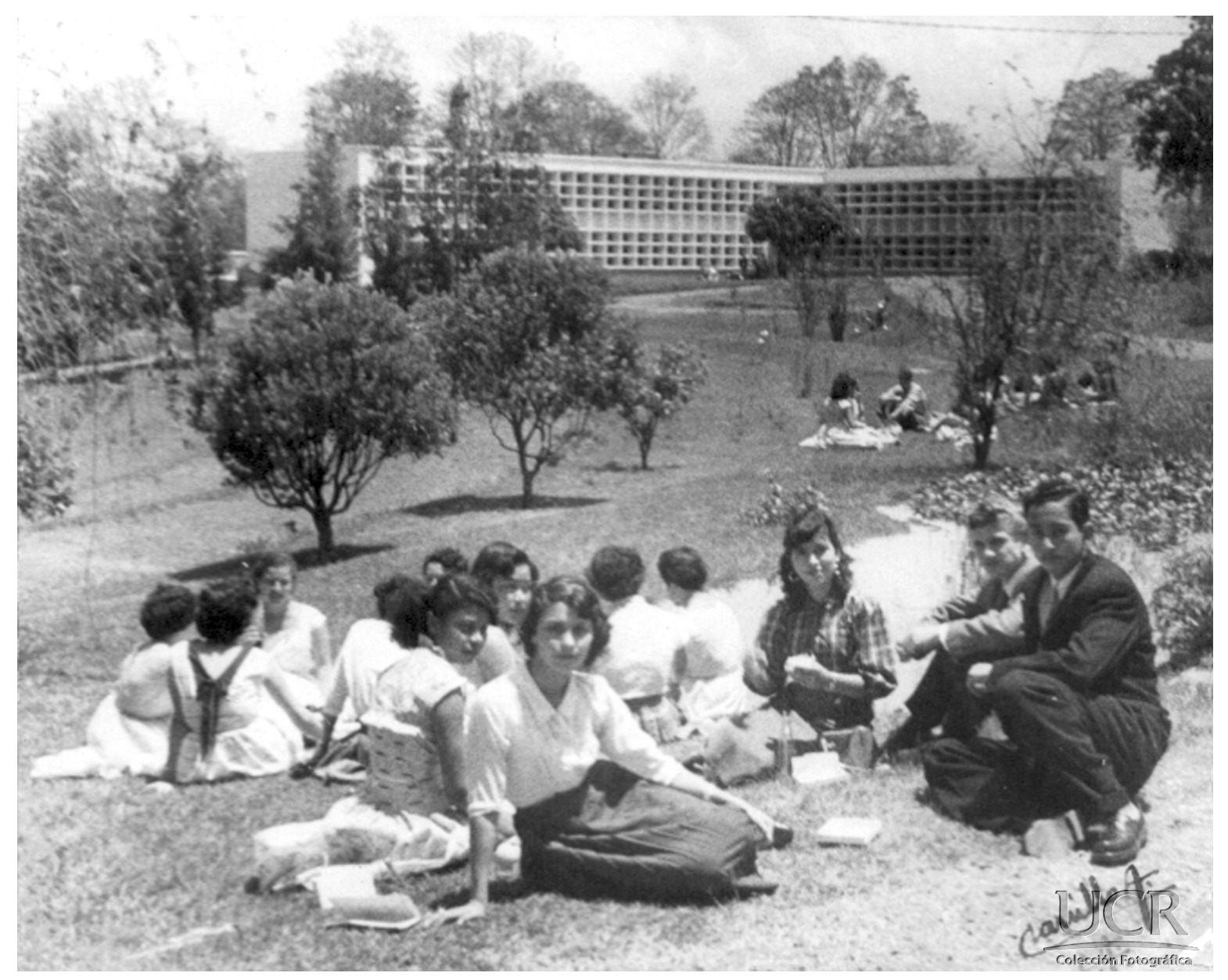

Esta es la razón por la que fue fácil que estos edificios se volvieran un ejemplo de las luchas por la modernización del país. Por abordar un ejemplo, es gracias a su escala, muy diferente a otros edificios del mismo estilo y época, lo que ha permitido una relación distinta entre el usuario y el objeto arquitectónico, en la que el usuario realmente se apropia del inmueble, ya que no se percibe masivo ni como bloque cerrado en contraste con sus homónimos de la CCSS, el Hospital México, etc.

Un aspecto relevante a tomar en cuenta es la temporalidad. A lo largo del tiempo la Universidad se configuró alrededor de este edificio, por ser el primero. Desde sus inicios fue el centro neurálgico de muchas actividades y el lugar de recepción de invitados (como el caso del presidente J. F Kennedy). Pero ahora, con el eventual traslado de la Facultad de Ingeniería, muchas de las actividades que históricamente se han asociado al edificio podrían desaparecer, lo que borraría parte de su valor simbólico.

Como parte de la construcción dentro del imaginario, se destacó el papel del edificio dentro de la emblemática tradición de la Pasada de Derecho-Ingeniería. Ahora que Ingeniería ya no estará en este lugar, ¿qué rol cumple la obra dentro de la construcción del imaginario social de espacio público al ser despojada de sus características históricas? Es aquí donde algunos criterios como: razón de ser, intención conceptual y contexto de la obra deben ser replanteados.

El edificio fue asignado al museo+UCR, institución que alberga, custodia, protege y difunde múltiples colecciones del acervo universitario. A pesar de existir formalmente desde el 2010, aunque sus antecedentes se remiten a la fundación de la Universidad, nunca ha contado con un espacio físico donde desarrollar a plenitud sus labores. El Consejo Universitario y la Rectoría les asignan el inmueble con la esperanza de convertir este espacio en un puente de diálogo entre el trabajo realizado por la Universidad y la población en general, esto gracias a las luchas del Museo para la valorización de trabajo. 
El edificio seguirá cumpliendo un rol educativo con su cambio a museo universitario; es más, con este cambio programático se vuelve aún más inclusivo, ya que es abierto no solo en uso del espacio, sino también en la misión educativa: el museo se proyecta a toda la población y no solo a los estudiantes de ingeniería.

El edificio seguirá dedicado a la formación, aunque de manera distinta, por lo que la intención conceptual y razón de ser se conservan, el rol dentro del imaginario colectivo como espacio para la difusión y educación se mantendrá, y posiblemente se refuerce.

El espacio público ciudadano no es un espacio residual entre calles y edificios. Tampoco es un espacio vacío considerado público simplemente por razones jurídicas. Ni un espacio "especializado", al que se ha de ir, como quien va a un museo o a un espectáculo. Mejor dicho estos espacios citados son espacios públicos potenciales, pero hace falta algo más para que sean espacios públicos ciudadanos (Borja, 2000, p. 7)

Partiendo de lo anterior, y en vista de que en la cotidianeidad del campus la imagen del edificio se ha borrado, es necesario consolidar su presencia dentro de la vida universitaria. Para lograr esta consolidación, y afianzándose en su estatus potencial de espacio público, hay que generar una dinámica real entre el edificio, el contexto y los usuarios. Esta dinámica se traduce en la necesidad de poner en valor las cualidades arquitectónicas del edificio histórico y la activación de los espacios circundantes mediante una intervención integral.

\section{Conclusión}

Partiendo de lo anterior, ¿qué papel jugó y juega el edificio para la Universidad y Costa Rica?. La Universidad se ha consolidado como un ejemplo a seguir para el país; para la población en general, la UCR sigue teniendo el baluarte intelectual y lo que ella proponga es aceptado y asimilado para el resto del territorio, lo anterior debido a la ardua labor que ha realizado en investigación y formación, además de que representa el saber académico de mayor nivel en el país. Así, las decisiones que la Institución tome en torno a su campus se verán reflejadas en la sociedad. Por lo tanto, es indispensable la valorización del edificio como obra en todas las dimensiones antes descritas para que sea un ejemplo de respeto por la historia y el aprovechamiento del patrimonio del país.

A manera de conclusión, el edificio de la Facultad de Ingeniería se ha configurado como un elemento de gran valor histórico, arquitectónico y simbólico dentro del campus; a partir de una lectura contemporánea, se puede rescatar su papel e importancia dentro del imaginario universitario y nacional.

La importancia de este rescate radica en la necesidad de conservar y proteger la historia, en términos de memoria y valor simbólico, para las nuevas generaciones. En un momento en que la UCR se enfrenta al crecimiento desmedido de la infraestructura, la puesta en valor de los espacios icónicos o que marcaron un hito en su historia se vuelve de primera necesidad en la lucha contra la pérdida del patrimonio tangible e intangible que resguarda el campus y la construcción de la identidad universitaria. Esto es de importancia institucional y nacional, y una deuda que tiene la Universidad, reflejada en la paupérrima situación a la que se enfrenta actualmente el patrimonio en el país como consecuencia de la inexistencia de políticas e investigaciones en esta área desde la academia.

El edificio se puede entender como un testimonio a pequeña escala de la historia de la Universidad: el resultado de una lucha por materializar la visión de un Estado en vías de desarrollo, un espacio que sigue cumpliendo su función educativa y formativa a pesar de las dificultades; y ahora es la oportunidad para darle un nuevo valor y capítulo en su historia, como un espacio para potenciar el legado nacional y ponerlo a disposición de la sociedad. El edificio como un monumento a la labor de la Universidad, y una conmemoración de su papel histórico y actual en la construcción del país:

Evidentemente, estas piezas propiamente urbanas, no requieren de la caracterización clásica del monumento: pedestal, figura, conmemoración, aunque alguna de ellas, por razones expositivas acabe en un pedestal 0 , por razones de conceptualización se fundamente en una conmemoración (Remesar, 1997, p. 105) 


\section{Referencias bibliográficas}

Acosta, E. (2012) Tipologías arquitectónicas. Revista ARQHYS. Obtenido el 1 febrero de 2017. Disponible en: www.arqhys.com/contenidos/arquitectonicas-tipologias. $\mathrm{html}$

Arroyo, C., Berlato, P. (2012). La comunicación. En Averbuj, D. Lengua castellana y Literatura. España: Oxford University Press.

Borja, J., Muxí, Z. (2000). El espacio público, ciudad y ciudadanía. Barcelona. Disponible en http://server2.docfoc.us/uploads/Z2015/11/18/7Cgehhzy6S/ ef5e25dfbfd1ae6214f17c9aaf00b3af.pdf

Carvajal, Silvia y Padilla, Arturo (2012) De palos, piedras y huevos: la pasada, una tradición de generaciones. En el blog enredate en semana U. Publicado el 2604-2012. Disponible en: enredateensemanau.blogspot.com/2012/04/de-palospiedras-y-huevos-la-pasada-una.htm

Chavarría, Gabriela (2011) La universidad que la biblioteca merece. Periódico Semanario Universidad (7 diciembre, 2011). Disponible en https://semanariouniversidad.com/ opinion/la-universidad-que-la-biblioteca-merece/

Chavarría, Gabriela (2012) ¿Privatización de los edificios universitarios?. Periódico Semanario Universidad (1 febrero, 2012). Disponible en http:// semanariouniversidad.ucr.cr/opinion/privatizacin-de-los-edificios-universitarios/

Dengo, M. E. (2001). Educación Costarricense. San José: EUNED.

Díaz, D. (13 de diciembre de 2015) Cuando John F. Kennedy puso a Costa Rica en el mapa de la Guerra Fría. Periódico La Nación. Disponible en: http://www.nacion. com/ocio/artes/John-Kennedy-Costa-Rica-Guerra_0_1530047005.html

Fernández, Andrés. (2010) La raíz del San José moderno. Revista Su Casa. No.55, 130-133.

Fernández, Andrés. (2011) Y llegó la modernidad. Revista Su Casa. No.59, 88-93.

Fernández, Andrés. (Junio 2015). Arquitectura(s) Moderna(s). Habitar No.79, 93-103.

Jankilevich, C. (2011). Laidentidad, el paisaje, el territorio y espacialidad de la Universidad de Costa Rica frente a la crisis de liderazgo en la búsqueda de respuestas a los grandes problemas nacionales", RevistArquis, (1).

Loos, A (1908) Ornamento y delito. Obtenido el 15 marzo de 2017. Disponible en: https:// www.disenoyarquitectura.net/2009/05/ornamento-y-delito-de-adolf-loos.html

Obregón, Rafael (1961) La Universidad de Santo Tomás (1843-1888). Revista de Filosofía de la UCR 3(9), 1961. Disponible en http://archivo.ucr.ac.cr/ustot.html

Remesar, Antoni (1997) Hacia una teoría delArte Público . Versión digital sin publicación. Consultado el 10 de junio de 2016. Disponible en: https://www.academia. edu/453848/1997.-Hacia_una_teor\%C3\%ADa_del_Arte_P\%C3\%BAblico

Tournikiotis, Panayotis (2001) Los historiadores del arte y las genealogías fundacionales: Pevsner, Kauffman y Giedion, en Historiografía de la Arquitectura Moderna. Librería Mairea y Celeste Ediciones S.A, Manuales Universitarios de Arquitectura. Traducción Jorge Sainz (2001). Madrid, España.

Vargas, J. coord. (2001). Enciclopedia de Costa Rica. Costa Rica: Grupo Océano.

Zúñiga, Randall (2013) UCR: Ciudad jardín contra ciudad parqueo. Revista Su Casa. Disponible en: www.revistasucasa.com/articulo/arquitectura/ucr-ciudad-jardíncontra-ciudad-parqueo

Zúñiga, Randall (2013) Verde Modernidad. Revista Su Casa. Disponible en: http://www. revistasucasa.com/articulo/arquitectura/verde-modernidad 